\title{
Estudo da paridade econômica e do desempenho energético de fachadas solares fotovoltaicas no extremo sul do Brasil
}

\author{
A study of the economic parity and energy performance \\ of solar photovoltaic façades in the south of Brazil
}

\section{Lívia Vasques Bender \\ Rodrigo Karini Leitzke \\ Julye Ramalho de Freitas \\ Eduardo Grala da Cunha \\ Isabel Tourinho Salamoni}

\section{Resumo \\ $\mathbf{M}$}

uitos países já projetam edificações eficientes e com necessidades baixas de consumo, principalmente através da energia solar fotovoltaica (FV). Entretanto, essa ainda é considerada uma fonte de alto investimento, principalmente no Brasil. Porém,

considerando que os revestimentos podem representar entre $6 \%$ e $20 \%$ do custo da edificação e, partindo do princípio que estes podem ser substituídos por módulos $\mathrm{FV}$, é importante que esse custo evitado seja computado no custo final desta tecnologia. $\mathrm{O}$ objetivo deste trabalho é analisar a paridade econômica e o desempenho energético de uma fachada solar fotovoltaica (FSFV) de um edifício comercial, comparada com outra revestida com materiais usuais da construção civil. A simulação do desempenho energético do edifício foi feita através do software EnergyPlus, e o cálculo da geração de energia da FSFV foi realizado com a utilização de dados de disponibilidade de radiação solar com base no programa Radiasol. Os resultados das simulações indicaram que uma FSFV comparada com fachadas usuais auxilia pouco na redução de consumo da edificação. Porém, contribui com o suprimento de 56,38\% desse consumo. A análise financeira parte da comparação entre sistemas usuais da construção civil com o sistema solar fotovoltaico (SFV), tendo um retorno de investimento, na melhor das hipóteses, de 4 anos.

'Lívia Vasques Bender Universidade Federal de Pelotas Pelotas - RS - Brasil

${ }^{2}$ Rodrigo Karini Leitzke 2Universidade Federal de Pelotas Pelotas - RS - Brasil

${ }^{3}$ Julye Ramalho de Freitas ${ }^{3}$ Universidade Federal de Pelotas Pelotas - RS - Brasil

${ }^{4}$ Eduardo Grala da Cunha ${ }^{4}$ Universidade Federal de Pelotas Pelotas - RS - Brasil

${ }^{5}$ Isabel Tourinho Salamoni ${ }^{5}$ Universidade Federal de Pelotas Pelotas - RS - Brasil

Recebido em 08/08/19 Aceito em 14/10/19
Palavras-chave: Sistema solar fotovoltaico. Simulação computacional. EmergyPlus.
Abstract
Many countries already design efficient buildings with low consumption needs, mainly through photovoltaic solar energy (PV). However, that is still considered a high-investment energy source, especially in Brazil. Nevertheless, considering that coatings can represent between 6 and $20 \%$ of the cost of a building, and assuming that they can be replaced by $P V$ modules, it is important that this avoided cost be included in the final cost of this technology. The aim of this study is to analyse the economic parity and the energy performance of a photovoltaic solar facade $(P V S F)$ of a commercial building, compared to one coated with usual building materials. The energy performance of the building was simulated using the EnergyPlus software and the PVSF energy generation calculation using solar radiation data by the Radiasol program. The simulation results indicated that an PVSF compared to usual façades does little to reduce building consumption. It does, however, contribute to the supply of $56.38 \%$ of that consumption. The financial analysis is based on a comparison between usual building systems and the photovoltaic solar system (PVS), with a return on the investment in, at best, 4 years.
Keywords: Photovoltaic solar system. Computer simulation. EnergyPlus. 


\section{Introdução}

Nos últimos anos, questões como o crescimento populacional, aliado ao crescente consumo energético, e as intensas alterações climáticas fizeram aumentar a preocupação com os impactos ambientais, causados pelos padrões de produção e de consumo da sociedade em que vivemos. Esses padrões, de uma forma global, são baseados em combustíveis fósseis, que geram emissões de poluentes, colocando em risco o suprimento em longo prazo do planeta (GOLDEMBERG; LUCON, 2007). Uma forma de evitar um impacto ainda maior ao meio ambiente, mantendo o fornecimento de energia, é diversificar esse suprimento, com ênfase às fontes renováveis de energia (FRE) (CARLO, 2008). Essas fontes vêm de recursos naturais, sendo reabastecidas naturalmente, como: eólica, hidráulica, biomassa, geotérmica, maremotriz e a solar. No contexto das FRE, o Brasil é um país privilegiado, uma vez que dispõe da maior bacia hidrográfica do mundo, de grandes florestas tropicais com áreas cultiváveis, de um potencial eólico promissor e, ainda, conta com seu território extenso para aproveitar a energia solar, que pode ser explorada de forma significativa (FRANCO, 2013). Dentre as FRE, a que mais apresenta possibilidades de integração com a envoltória das edificações é a energia solar FV, em razão de seu avanço tecnológico e, principalmente, facilidade de instalação e grande capacidade de operação em edificações (DÁVI, 2013). No sistema FV (SFV), as células FV convertem a luz solar em energia elétrica, de forma silenciosa e sustentável, tendo um impacto mínimo. Esses módulos podem ser sobrepostos ao sistema de vedação da edificação - BAPV (Building Applied Photovoltaics) ou substituir elementos construtivos e/ou revestimentos da edificação - BIPV (Building Integrated Photovoltaics).

Os edifícios comerciais são uma opção viável para o uso integrado dos SFV, pois além de apresentarem alto consumo de energia elétrica, em função da demanda em iluminação, equipamentos e da climatização artificial, existe sincronicidade entre a geração e o consumo. A curva de carga de consumidores comerciais tem como característica um consumo durante o horário comercial (diurno) com uma pequena queda no período correspondente ao almoço. O consumo de eletricidade no setor comercial é caracterizado justamente no período em que o SFV está produzindo energia. Sendo assim, a instalação de SFV em edifícios comerciais de escritórios interligados à rede é um exemplo de aplicação ideal (RÜTHER, 2004). Esses edifícios apresentam: “(1) grande disponibilidade de área nas fachadas para geração; (2) consumo elevado de energia por metro quadrado e (3) maior disponibilidade de capital para investimento em geração fotovoltaica, quando comparado com o setor residencial [...]” (SANTOS, 2015, p. 21).

Por outro lado, na sua grande maioria, os edifícios de escritório são verticais, com muitas unidades consumidoras independentes, ou seja, pouca área de cobertura para uma grande área de fachada. Sendo assim, as coberturas, local ideal para instalação de SFV em baixas latitudes, não seriam capazes de abrigar sistemas com grandes potências nominais. Em contrapartida, “[...] as fachadas aparecem como uma oportunidade para geração de eletricidade, através da tecnologia fotovoltaica integrada na arquitetura (BIPV) [...]" (SANTOS, 2015), de forma a complementar a capacidade instalada, ou de gerar energia com um percentual menor de contribuição no suprimento do consumo. É importante salientar que a utilização de SFV em fachadas não é a melhor opção de implantação para o Brasil, em virtude de as latitudes serem baixas, variando de $0^{\circ}$ (ao norte) até $32^{\circ}$ (ao sul do Brasil). Além disso, os centros urbanos são mais densos e verticais, podendo haver maior sombreamento das fachadas. Por outro lado, mesmo que o sistema não seja capaz de gerar o seu máximo de energia, haverá alguma geração. Se o usuário puder optar, por exemplo, entre revestir sua edificação com um material que apenas cumpra requisitos estéticos ou outro, capaz de gerar energia elétrica e, em curto e médio prazo, agregar benefícios econômicos, já é uma grande vantagem. Partindo do princípio de que os revestimentos são considerados um dos itens percentualmente mais caros no orçamento de uma obra, isso já seria uma economia de investimento, que deve ser computada na análise de custo final. Dependendo do tipo de material e das características da construção, o envelope representa entre 6\% e 20\% do custo da edificação (MEDEIROS, 2012). Além disso, “[...] os custos de instalação de equipamentos solares FV estão diminuindo rapidamente, enquanto que os custos dos efeitos externos do uso de fontes convencionais (isto é, usinas hidrelétricas) continuam a aumentar [...]" (ECHEGARAY, 2014, p. 125), assim como os custos referentes às tarifas convencionais de energia elétrica.

Quanto à integração de sistemas fotovoltaicos com a envoltória, Dias (2014), Heinstein et al. (2013) e Strong (2010) discutem os aspectos tecnológicos e arquitetônicos desse processo de integração. Segundo os autores, é fundamental que haja entendimento sobre a necessidade de individualizar o contexto em que a integração será realizada. Para isso, é necessário considerar os aspectos geográficos, construtivos e dos tipos de usuários, de modo a garantir melhor qualidade dos projetos fotovoltaicos incorporados à envoltória dos edifícios. 
Lai e Hokoi (2015) realizaram um trabalho de revisão dos estudos realizados durante a última década em fachadas solares transparentes e translúcidas, destacando as categorias de fachadas ventiladas e fachadas fotovoltaicas integradas. Sobre os sistemas fotovoltaicos integrados em edifícios, os estudos considerados pelos autores revelam que essa estratégia de integração fornece eletricidade, luz natural e calor para o edifício; entretanto, salientam que se trata de uma tecnologia em estágio inicial de desenvolvimento, carecendo de trabalhos que discutam as melhores alternativas para sua aplicação e seus respectivos custos.

A fim de identificar estratégias para atingir um edifício com necessidades energéticas próximas a zero (nZEB), Medved et al. (2019) apresentaram uma estrutura alternativa de fachada. A estrutura consiste em um vidro multicamada de seis painéis com células fotovoltaicas integradas na camada externa (BIPV). Foi avaliado o desempenho energético durante todo o ano dessa estrutura de acordo com as necessidades de energia de aquecimento, refrigeração e produção de eletricidade. De acordo com os resultados obtidos pelos autores, a partir de experimentos feitos por meio de simulações computacionais, as necessidades energéticas do edifício são reduzidas significativamente. Além disso, a transmitância térmica das estruturas avaliadas nas fachadas pode ser comparada com as transmitâncias térmicas de estruturas opacas de fachadas preconizadas pela maior parte dos regulamentos europeus, o que possibilita uma configuração de fachada nos edifícios utilizando uma estrutura semitransparente com geração eficiente de energia elétrica.

Ainda sobre a busca por edifícios com baixas necessidades energéticas, Domjan et al. (2019) apresentam um método para a modelagem rápida de indicadores de eficiência energética de edifícios construídos com grandes áreas envidraçadas (semelhante ao vidro proposto por Medved et al. (2019), apresentado no parágrafo anterior), com múltiplas camadas nas estruturas das fachadas fotovoltaicas integradas (BIPV). De acordo com os resultados obtidos pelos autores, observou-se que edifícios que apresentam grande proporção de fachada envidraçada e até edifícios totalmente envidraçados podem atender aos requisitos nZEB por meio da produção local de eletricidade com a estrutura da fachada BIPV, desde que a composição dessa fachada considere tecnologias construtivas com vidros múltiplos com geração fotovoltaica.

Didoné et al. (2014) apresentaram um estudo no qual a contribuição da energia solar para a transformação de edifícios de escritórios brasileiros em edifícios ZEB foi analisada em duas cidades: Florianópolis e Fortaleza. A aplicação de diversas tecnologias FV em diferentes partes da envoltória possibilitou a avaliação de seu potencial quando aplicado em diferentes inclinações e orientações. O destaque nesse estudo foram os vidros FV semitransparentes, pois demonstraram ser uma boa alternativa para a substituição destes em janelas com vidros tradicionais. Os SVFV contribuíram com $21 \%$ da energia gerada em Florianópolis e $11 \%$ em Fortaleza, embora os módulos utilizados tivessem uma eficiência de apenas $3 \%$.

Sorgato et al. (2018) apresentaram um estudo sobre o potencial técnico e econômico na substituição dos materiais convencionais por módulos solares fotovoltaicos em uma fachada e no telhado de um edifício comercial em seis cidades brasileiras. Os resultados apresentados pelos autores apontam que, para análise técnica, é possível atender plenamente à demanda de energia do edifício com integração fotovoltaica em todas as cidades brasileiras avaliadas. Do ponto de vista econômico a análise mostrou que, com os custos decrescentes da energia fotovoltaica, a substituição de materiais de construção de fachadas convencionais por módulos fotovoltaicos não é apenas uma abordagem inovadora, mas também um potencial benefício econômico.

Agathokleous e Kalogirou (2015) organizaram uma revisão sobre as configurações e características de transferência de calor para fachadas de dupla pele e BIPV. Segundo os autores, essas fachadas podem ser usadas de várias maneiras: para fornecer uma zona de amortecimento térmico, pré-aquecimento solar de ar de ventilação, economia de energia, proteção de som, proteção de vento e poluentes, refrigeração noturna e espaço para dispositivos de coleta de energia como células FV. Os autores descobriram que a maioria das pesquisas envolve as fachadas mecanicamente ventiladas devido à flexibilidade do sistema. Esse sistema conduz o ar, podendo ser personalizado para operar em diferentes condições para diferentes aplicações, o que não acontece com sistemas de ventilação natural, pois o fluxo natural, como não se tem controle, pode não ser adequado para resfriar os módulos ou conduzir naturalmente o ar interno para o aquecimento de espaços. Nas pesquisas analisadas, os pesquisadores acabam por concordar que o melhor espaçamento de ar entre os módulos FVs e a fachada do edifício varia entre $10 \mathrm{~cm}$ e $15 \mathrm{~cm}$, a fim de manter a temperatura dos módulos em níveis baixos. É apontado que há muitos estudos realizados na análise de transferência de calor de fachadas de pele dupla, mas muito poucos realizados nas fachadas BIPV e, especialmente, para o caso de convecção natural. Ressaltam que, particularmente, no que diz respeito à análise de transferência de calor com coeficientes de convecção natural, não há estudos nas fachadas solares. 
Peng et al. (2011) analisaram aspectos de design arquitetônico dos sistemas BIPV, incluindo como projetar a vida útil dos sistemas e como escolher BIPV ou BAPV. Os autores também criaram uma nova estrutura de montagem para resolver problemas relacionados à manutenção e substituição de componentes FV. Concluiuse que a função, o custo, a tecnologia e a estética são mais importantes do que a alta integração. Também foi mencionado que, devido à menor vida útil dos SFVs em relação à vida útil dos edifícios (50 anos), a manutenção fácil e a substituição dos módulos FV são importantes.

Buscando evidenciar a viabilidade econômica de edifícios solares FV em relação à utilização de outros materiais da construção civil, Oliver e Jackson (2001) realizaram um estudo utilizando a metodologia da análise dos custos evitados. Esse estudo foi realizado para ilustrar as vantagens da integração de elementos FV a prédios urbanos. Considerando o custo evitado pela utilização de elementos FV em substituição a um sistema convencional de revestimento de vidro de $10 \mathrm{~mm}$, os edifícios solares apresentaram o melhor desempenho econômico. Os autores afirmam que ao comparar os sistemas BIPVs com outros revestimentos, deve-se levar em consideração a função da proteção contra as intempéries e a eletricidade gerada. Já numa comparação dos custos energéticos e econômicos do sistema BIPV com outras opções de fornecimento de eletricidade deve-se ter em conta os custos energéticos e econômicos associados aos materiais de revestimento evitados.

Para Ferreira, Scomparin e Carignani (2010), a aplicação do método dos custos substituídos é adequada para edifícios em fase anterior à construção, etapa em que não foram adquiridos ou instalados os materiais a serem substituídos pelos módulos FV. Em estudo sobre a viabilidade econômica e energética de janelas FV em edifícios mato-grossenses foram analisados três edifícios públicos com grandes áreas de fachadas envidraçadas com condições adequadas para receber painéis FV. Esses permitiriam gerar aproximadamente $3,5 \%$ da energia consumida anualmente, por um custo $7 \%$ maior do que o da aplicação da vedação de vidro, permitindo concluir que a opção de instalação de painéis FV é viável econômica e energeticamente, maximizando a eficiência energética da edificação.

Yang e Zou (2015) avaliaram a tecnologia BIPV em termos de seus custos, benefícios, riscos, barreiras e possíveis estratégias de melhoria. Sobre os custos a conclusão foi que o custo direto do sistema é alto, não importando o país. Entre os benefícios apontados estão aspectos ambientais e de saúde através da redução das emissões de carbono, e os sociais, como a redução do uso da terra para geração de eletricidade. Já para os usuários, destacam as compensações de custos de material de construção e economia de contas na instalação do sistema BIPV. Afirmam que esses benefícios levam a vários riscos relacionados a custos e barreiras que afetam o crescimento contínuo do mercado BIPV, e para aumentar as aplicações do BIPV é importante diminuir os custos, que são praticamente dependentes de ter a política correta e o apoio de incentivo dos principais membros da cadeia de suprimentos. Também identificaram em sua pesquisa o fato de que existe a falta de dados detalhados sobre o custo do BIPV (incluindo os custos dos componentes individuais) e a falta de métodos para a análise custo-benefício do BIPV, trazendo riscos e barreiras em suas aplicações. Esse fato acabou por limitar este trabalho.

A partir da problemática do potencial fotovoltaico, que desempenha um papel crítico no desenvolvimento de políticas de planejamento e esquemas de financiamento para a implantação bem-sucedida de sistemas fotovoltaicos nas cidades, Catita et al. (2014) consideraram as áreas significativas disponíveis nas fachadas das modernas paisagens urbanas, como instrumento para identificar estratégias locais/municipais para o melhor aproveitamento da irradiação solar em paredes verticais. O estudo buscou apresentar uma metodologia computacional através de uma ferramenta 3D para identificar quais partes (coberturas e/ou fachadas) de um edifício são mais favoráveis para a instalação de módulos solares, bem como a área disponível para a instalação.

Gaviria et al. (2013) discutiram a influência da configuração urbana na geração fotovoltaica com sistemas integrados às fachadas. O trabalho analisou a aplicação de módulos fotovoltaicos em diferentes configurações urbanas, levando também em consideração o papel do entorno edificado. Através de simulações computacionais realizadas em diferentes configurações urbanas para avaliar o potencial de geração fotovoltaica em superfícies verticais opacas, os autores concluíram que a determinação da eficiência dos modelos testados depende diretamente da disponibilidade de superfícies para a geração FV (fachadas ou fachadas e cobertura), bem como o contexto em que o edifício está inserido dentro do perímetro urbano.

O objetivo geral deste estudo é analisar a paridade econômica e o desempenho energético de uma FSFV de um edifício comercial comparada a uma fachada revestida com materiais usuais da construção civil na zona bioclimática brasileira 2 .

492 Bender, L. V.; Leitzke, R. K.; Freitas, J. R. de; Cunha, E. G. da; Salamoni, I. T. 


\section{Método}

O método do trabalho foi dividido em sete etapas que estão ilustradas na Figura 1.

\section{Definição do objeto de estudo}

Para o estudo optou-se por utilizar um modelo computacional já desenvolvido para simulação, caracterizando-o como referência e possibilitando trabalhos futuros com outros enfoques. Foi escolhido como modelo base o desenvolvido por Carlo (2008), em função de seu estudo sobre volumetrias típicas na paisagem urbana em diferentes capitais brasileiras, para atividades não residenciais. Nesse estudo a autora desenvolveu modelos representativos de cada atividade proposta. Dessa maneira, foi selecionado o modelo denominado "representativo de grandes escritórios". Esse modelo tem dimensões retangulares $(27,00 \mathrm{~m} \mathrm{x}$ $7,80 \mathrm{~m})$ e é divido em duas salas por andar com circulação vertical centralizada. No total são cinco pavimentos com pé-direito de 2,60 m cada (Figura 2).

Figura 1 - Etapas do método

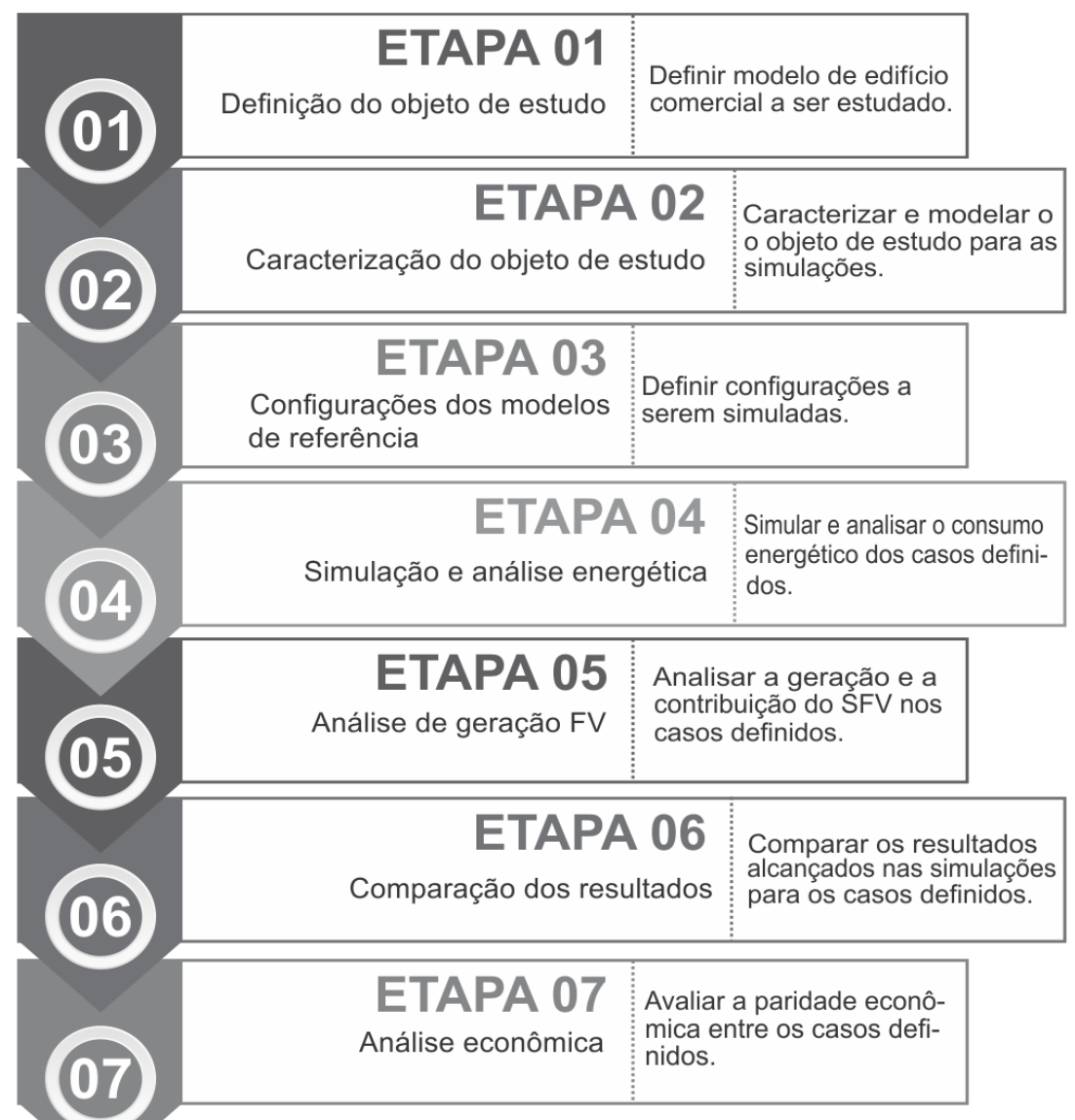

Figura 2 - Planta baixa do edifício modelo

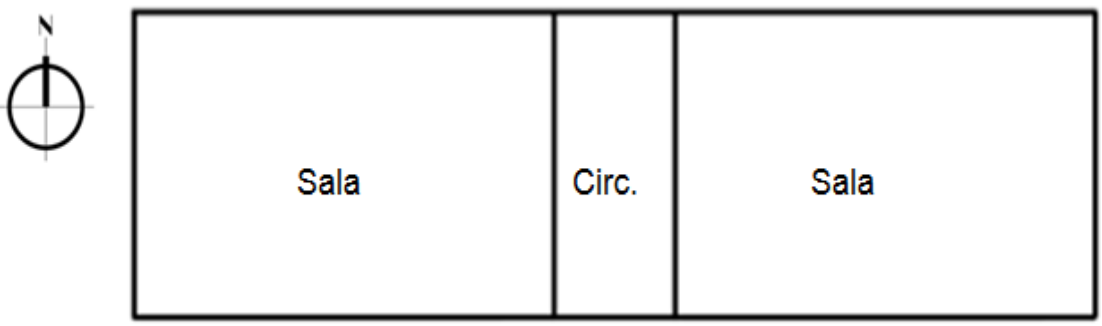

Fonte: Carlo (2018). 


\section{Caracterização do objeto de estudo}

A modelagem da edificação foi realizada no programa SketchUp Make 2016, com o plugin Legacy OpenStudio, versão 1.0.13. O modelo base apresenta as maiores fachadas orientadas para norte-sul e cada compartimento foi considerado uma zona térmica (Figura 3). As zonas com atividade-fim são condicionadas e as centrais não. As dimensões das zonas térmicas foram caracterizadas pelas superfícies externas das paredes externas até o eixo das paredes internas.

\section{Configurações do modelo de referência}

\section{Uso e ocupação}

As configurações utilizadas como dados de entrada no programa foram baseadas em Carlo (2008). As cargas internas reproduzem as taxas máximas de calor dissipadas pelos elementos internos da edificação que contribuem para a carga térmica. São eles: pessoas, equipamentos e iluminação (ARA, 2010).

Assim, para a presente simulação, os principais dados do calor dissipado internamente são apresentados na Tabela 1.

Foi considerada apenas a utilização e ocupação nos dias úteis (de segunda a sexta-feira). Aos sábados e domingos a edificação é considerada desocupada, tendo seus sistemas desligados, exceto nas simulações que envolvem o SFV, considerado como gerando energia ao longo dos sete dias da semana. No padrão de uso, as atividades na edificação começam às $8 \mathrm{~h} 00 \mathrm{~min}$ da manhã, tendo intervalo às $12 \mathrm{~h} 00 \mathrm{~min}$. A retomada das atividades se dá às $14 \mathrm{~h} 00 \mathrm{~min}$, com término às $18 \mathrm{~h} 00 \mathrm{~min}$. Já os equipamentos são ligados às $8 \mathrm{~h} 00 \mathrm{~min} \mathrm{e}$ desligados às 18h00min, enquanto a iluminação é acionada a partir das 8h00min e desligada às 22h00min.

\section{Climatização artificial}

Seguindo as configurações de Carlo (2008), a taxa de infiltração de ar considerada foi de meia renovação total a cada hora. As temperaturas limites estabelecidas foram de $18{ }^{\circ} \mathrm{C}$ para aquecimento e $24{ }^{\circ} \mathrm{C}$ para resfriamento e o dimensionamento do sistema de condicionamento de ar considerou o comando autosize do programa. O contato do piso com o solo foi considerado isolado (subsolo) e o entorno urbano e o sombreamento não foram considerados devido ao seu aspecto dinâmico e variável.

\section{Arquivo climático}

Para a simulação no programa EnergyPlus foi necessária a definição de dados climáticos e geográficos em relação aos quais o comportamento do edifício seria analisado. O arquivo climático TRY (Test Reference Year) utilizado foi o da cidade de Pelotas, RS. Na Tabela 2 são apresentadas as informações geográficas adotadas na simulação.

As normais climatológicas do município de Pelotas, RS, para o período de 1971 a 2000, são apresentadas na Tabela 3.

Dessa forma, a carga térmica interna da edificação foi calculada para as condições climáticas da cidade, tornando possível estimar o consumo de energia elétrica relativa ao condicionamento térmico artificial, bem como aos demais sistemas instalados na edificação.

Figure 3 - Modelagem e zonas térmicas da edificação
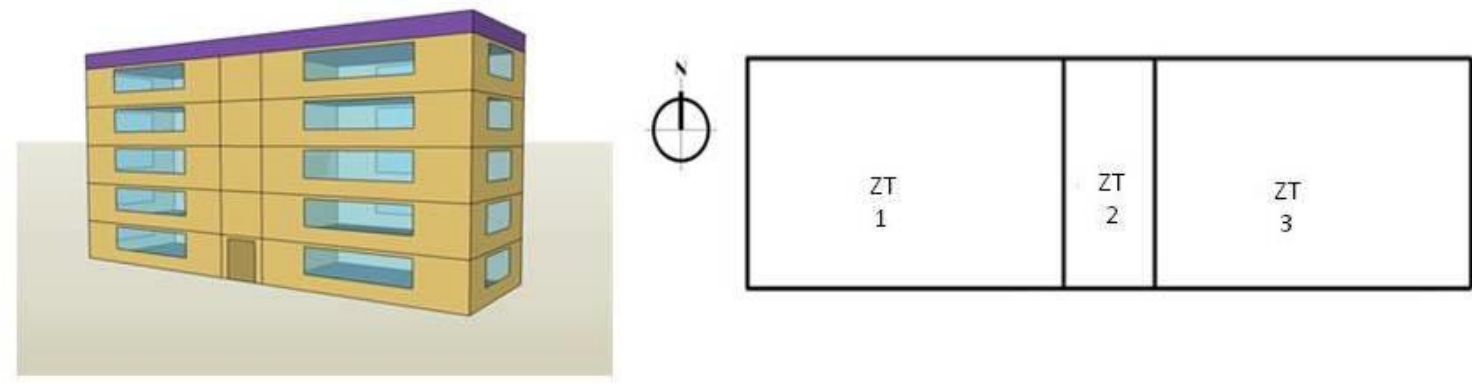

494 Bender, L. V.; Leitzke, R. K.; Freitas, J. R. de; Cunha, E. G. da; Salamoni, I. T. 
Tabela 1 - Caracterização das densidades de carga interna utilizadas no modelo

\begin{tabular}{|c|c|}
\hline Parâmetro & Variáveis \\
\hline DCI equipamentos & $9,60 \mathrm{~W} / \mathrm{m}^{2}$ \\
\hline Densidade de pessoas & 19,57 m²/pessoa, carga leve/média NBR 16401 (ABNT, 2008) \\
\hline Potência de iluminação & $6,70 \mathrm{~W} / \mathrm{m}^{2}$ \\
\hline
\end{tabular}

Tabela 2 - Informações geográficas de Pelotas

\begin{tabular}{c|c}
\hline Local & Pelotas, RS \\
\hline Características do entorno & Cidade (urbano) \\
Latitude & $-31,46^{\circ}$ \\
Longitude & $-52,20^{\circ}$ \\
Altitude & $17 \mathrm{~m}$ \\
\hline
\end{tabular}

Tabela 3 - Normais climatológicas do município de Pelotas, RS, Brasil

\begin{tabular}{|c|c|c|c|c|c|c|c|c|c|c|c|c|c|}
\hline Variáveis & Jan & Fev & Mar & Abr & Mai & Jun & Jul & Ago & Set & Out & Nov & Dez & Anual \\
\hline Temperatura Média $\left({ }^{\circ} \mathrm{C}\right)$ & 23,2 & 23 & 21,7 & 18,5 & 15,1 & 12,4 & 12,3 & 13,4 & 14,9 & 17,5 & 19,6 & 22 & 17,8 \\
\hline $\begin{array}{l}\text { Temperatura Média das Minimas } \\
\left.{ }^{\circ} \mathrm{C}\right)\end{array}$ & 19,1 & 19,1 & 17,7 & 14.4 & 11,1 & 8.6 & 8.6 & 9,5 & 11,2 & 13,6 & 15,3 & 17,7 & 13,8 \\
\hline $\begin{array}{l}\text { Temperatura Minima Absoluta } \\
\left({ }^{\circ} \mathrm{C}\right)\end{array}$ & 10 & 9,8 & 5 & 2,7 & 1,2 & -3 & $-2,7$ & -1 & 0,2 & 2,6 & 6 & 7,9 & -3 \\
\hline $\begin{array}{l}\text { Temperatura Média das Máximas } \\
\left({ }^{\circ} \mathrm{C}\right)\end{array}$ & 28,2 & 27,9 & 26,9 & 24 & 20,8 & 17,8 & 17,5 & 18,6 & 19,6 & 22,2 & 24,6 & 27,1 & 22,9 \\
\hline $\begin{array}{c}\text { Temperatura Máxima Abs oluta } \\
\left({ }^{\circ} \mathrm{C}\right)\end{array}$ & 39 & 36,5 & 37,4 & 35,1 & 31,6 & 29,4 & 31,8 & 33 & 35,6 & 34,4 & 39,2 & 39,6 & 39,6 \\
\hline Precipitaçăo Pluviométrica $(\mathrm{mm})$ & 119,1 & 153,3 & 97,4 & 100,3 & 100,7 & 105,7 & 146 & 117,4 & 123,7 & 100,7 & 99,5 & 103,2 & 1366,9 \\
\hline $\begin{array}{l}\text { Precipitaçăo Máxima em } 24 \text { horas } \\
(\mathrm{mm})\end{array}$ & 82 & 188,2 & 126,8 & 134 & 86 & 95 & 109,8 & 92,2 & 92 & 74,7 & 81,6 & 152 & 188,2 \\
\hline Número de dias de Precipitação & 11,7 & 11,5 & 10,3 & 8,9 & 9,2 & 10,5 & 11,4 & 9,7 & 10,8 & 10,6 & 10 & 9,5 & 124,1 \\
\hline Umidade Relativa $(\%)$ & 77,4 & 79,9 & 80,5 & 82,3 & 83,6 & 84 & 84,9 & 83,2 & 81,8 & 79,5 & 76 & 75,5 & 80,7 \\
\hline $\begin{array}{l}\text { Evaporaçăó Tanque Classe "A" } \\
(\mathrm{mm})\end{array}$ & 205,3 & 161 & 149,3 & 106,2 & 71,9 & 56,5 & 62 & 76,9 & 100,8 & 143,9 & 179,6 & 215,6 & 1529,1 \\
\hline Evaporaçăo Piche (mm) & 161,4 & 123,8 & 123,7 & 95,4 & 74,6 & 61 & 63,8 & 78,2 & 96,8 & 126,2 & 149,9 & 168,8 & 1323,6 \\
\hline 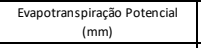 & 153,4 & 121,3 & 111,1 & 75 & 51,1 & 36,8 & 40,1 & 54 & 72,4 & 103,7 & 130,4 & 153,7 & 1103,1 \\
\hline Insolação Total (horas e éécimos) & 251,2 & 204,7 & 213 & 189,5 & 177,7 & 146,2 & 149,9 & 160,8 & 161,5 & 199,6 & 234,5 & 265,9 & 196,2 \\
\hline $\begin{array}{c}\text { Radiação Solar Global(cal.cm -2 } \\
\text {.dia-1) }\end{array}$ & 498,2 & 439,3 & 377,3 & 297,2 & 225,7 & 184 & 190 & 238,8 & 299,2 & 385,9 & 478,2 & 524,1 & 344,8 \\
\hline Nebulosidade $(0-10)$ & 5,7 & 5,9 & 5,6 & 5,3 & 5,5 & 6 & 6,3 & 6,3 & 6,4 & 6,1 & 5,8 & 5,4 & 5,9 \\
\hline Pressão Barométrica (kPa) & 101,1 & 101,3 & 101,4 & 101,5 & 101,7 & 101,7 & 101,9 & 101,8 & 101,8 & 101,5 & 101,3 & 101,2 & 101,5 \\
\hline $\begin{array}{l}\text { Velocidade Média do Vento (m.s- } \\
1 \text { ) }\end{array}$ & 3,9 & 3,6 & 3,2 & 3 & 2,7 & 2,8 & 3 & 3,2 & 4 & 4,2 & 4,2 & 4 & 3,5 \\
\hline Direçăo Predominante do Vento & $\mathrm{NE}$ & $\mathrm{E}$ & $\mathrm{E}$ & sw & sw & sw & $\mathrm{NE}$ & $\mathrm{NE}$ & $\mathrm{NE}$ & $\mathrm{E}$ & $\mathrm{E}$ & $\mathrm{E}$ & $\mathrm{E}$ \\
\hline $\begin{array}{l}\text { Velocidade Máxima do Vento } \\
\text { (m.s-1) }\end{array}$ & 23 & 25,2 & 25 & 25,5 & 23,5 & 26 & 23 & 28 & 30 & 27,2 & 26,2 & 27,2 & 30 \\
\hline Direção do Vento na Vel. Máxima & sw & s & sw & sw & $\mathrm{NE}$ & $\mathrm{s}$ & sw & $\mathrm{NE}$ & $\mathrm{NE}$ & $\mathrm{NE}$ & s & sw & NE \\
\hline Número de Dias de Geada & 0 & 0 & 0 & 0,4 & 3,2 & 6,5 & 5,7 & 4,7 & 2,7 & 0,7 & 0,1 & 0 & 23,9 \\
\hline Número de Dias de Granizo & 0 & 0,2 & 0,1 & 0 & 0 & 0,2 & 0,3 & 0,1 & 0,3 & 0,1 & 0,2 & 0,1 & 1,6 \\
\hline Número de Dias de Orvalho & 11,1 & 11,4 & 12,5 & 9,7 & 7,5 & 4,8 & 3,9 & 5,6 & 6,3 & 9,1 & 10,2 & 11,6 & 103,2 \\
\hline Número de Dias de Nevoeiro & 2 & 3 & 5,1 & 9,2 & 10,3 & 8,3 & 9,8 & 9,5 & 5,6 & 3,2 & 1,7 & 1,8 & 64,2 \\
\hline
\end{tabular}

Fonte: Universidade Federal de Pelotas (2019).

Pelotas se encontra na zona bioclimática brasileira 2 (ZBB2). A ZB2 apresenta clima temperado com verão e inverno bem definidos e se encontra em uma alta latitude $\left(-31,46^{\circ}\right)$ sendo uma das melhores regiões para inserção de módulos FV em fachadas (inclinação $90^{\circ}$ ).

\section{Envoltória: características construtivas}

As especificações dos elementos construtivos estão descritas na Tabela 4.

Entretanto, o software EnergyPlus não entende fechamentos compostos por camadas heterogêneas, como o que acontece em paredes em alvenaria cerâmica, para isso uma parede equivalente deve ser criada com as mesmas propriedades de transmitância térmica e capacidade térmica da parede real. A Figura 5, de Ordenes et al. (2003), ilustra a transformação de uma parede real para uma parede equivalente.

A partir deste procedimento obteve-se a composição das paredes confome a Tabela 5. A Tabela 6 apresenta a composição da cobertura.

O percentual de área de janela foi considerado de $25 \%$ nas fachadas. Para o fator solar do vidro (FS) adotouse 0,83 (CARLO, 2008). 
Tabela 4 - Materiais construtivos do modelo base

\begin{tabular}{l|c|c}
\hline Componentes & Materiais & Espessura (cm) \\
\hline \multirow{3}{*}{ Paredes } & Argamassa interna & 2,0 \\
\cline { 2 - 3 } & Tijolo cerâmico & 10,0 \\
\cline { 2 - 3 } & Argamassa externa + pintura cor clara & 2,5 \\
\hline \multirow{4}{*}{ Cobertura } & Fibrocimento & 0,6 \\
\cline { 2 - 3 } & Poliestireno extrudado & 3,0 \\
\cline { 2 - 3 } & Fibrocimento & 0,6 \\
\cline { 2 - 3 } & Câmada de ar & - \\
\cline { 2 - 3 } & Laje de concreto & 10,0 \\
\hline Janela & Vidro simples & $\mathbf{0 , 3}$ \\
\hline
\end{tabular}

Fonte: Carlo (2018).

Figura 5 - Parede equivalente

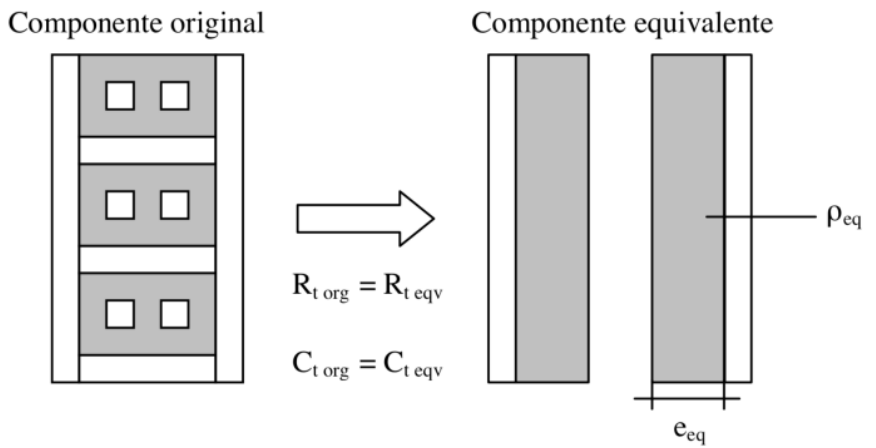

Fonte: Ordenes et al. (2003).

Nota: Legenda:

$\mathrm{R}_{\mathrm{t}}$ : resistência térmica de superfície à superfície $\left[\left(\mathrm{m}^{2} \mathrm{~K}\right) / \mathrm{W}\right]$;

$\mathrm{C}_{\mathrm{t}}$ : capacidade térmica $\left[\mathrm{kJ} /\left(\mathrm{m}^{2} \mathrm{~K}\right)\right]$;

$e_{\text {eq }}$ : espessura equivalente $[\mathrm{m}] ; \mathrm{e}$

$\rho_{\text {eq }}$ : densidade de massa aparente da camada equivalente $\left[\mathrm{kg} / \mathrm{m}^{3}\right]$.

Tabela 5 - Composição das paredes do modelo base

\begin{tabular}{|c|c|c|c}
\hline \multirow{2}{*}{ Material } & $\begin{array}{c}\text { Espessura } \\
(\mathbf{e}): \mathbf{m}\end{array}$ & $\begin{array}{c}\text { Condutividade } \\
(\boldsymbol{\lambda}) \mathbf{:} \mathbf{W} / \mathbf{m} . \mathbf{K})\end{array}$ \\
\cline { 2 - 4 } & Reboco & 0,025 & 1,15 \\
\cline { 2 - 4 } & Alvenaria cerâmica & 0,015 & 0,70 \\
\cline { 2 - 4 } & Câmara de ar & \multicolumn{2}{|c|}{$\begin{array}{c}\text { Resistência térmica } \\
\text { de } 0,16 \mathrm{~m}^{2} . \mathrm{K} / \mathrm{W}\end{array}$} \\
\cline { 2 - 4 } & Alvenaria cerâmica & 0,015 & 0,70 \\
\cline { 2 - 4 } & Argamassa & 0,020 & 1,15 \\
\hline
\end{tabular}

Tabela 6 - Composição da cobertura do modelo base

\begin{tabular}{|c|c|c|c|}
\hline & Material & $\begin{array}{c}\text { Espessura } \\
(\mathrm{e}): \mathrm{m}\end{array}$ & $\begin{array}{l}\text { Condutividade } \\
(\lambda): W /(\mathrm{m} . K)\end{array}$ \\
\hline & Fibrocimento & 0,006 & 1,00 \\
\hline & Poliestireno expandido & 0,03 & 0,035 \\
\hline & Fibrocimento & 0,006 & 1,00 \\
\hline $\mathrm{He}$ & Câmara de ar & \multicolumn{2}{|c|}{$\begin{array}{c}\text { Resistência térmica } \\
\text { de } 0,21\left(\mathrm{~m}^{2} \cdot \mathrm{K}\right) / \mathrm{W}\end{array}$} \\
\hline & Argamassa & 0,020 & 1,15 \\
\hline
\end{tabular}

496 Bender, L. V.; Leitzke, R. K.; Freitas, J. R. de; Cunha, E. G. da; Salamoni, I. T. 


\section{Método de simulação no EnergyPlus}

A partir do modelo base, as paredes voltadas para o norte foram configuradas no objeto Construction:InternalSource, módulo do EnergyPlus que permite a configuração de elementos geradores FV, possibilitando a especificação dos módulos, considerando ainda as outras camadas da parede equivalente (Tabela 7).

As camadas foram inseridas como nos exemplos existentes nas referências do EnergyPlus. Pode-se observar que existe a redução na transmitância térmica das paredes da fachada norte, ou seja, o aumento da resistência térmica da parede aletar, assim, a demanda térmica interna e o consumo de eletricidade pelo sistema de ar condicionado, além de gerar energia elétrica.

\section{Modelos simulados}

A partir da definição da abordagem inicial da simulação do edifício com e sem módulos $\mathrm{FV}$, foram definidas 8 situações a serem testadas conforme Figura 6, tendo definida como variável principal o tipo de módulo: FV opaco e VFV. Essas opções levaram em conta o envelope, no qual a partir de um modelo base têm-se diferentes possibilidades de substituição de materiais usuais pela utilização da tecnologia $\mathrm{FV}$, tanto na parte opaca (em substituição ao revestimento convencional, como o alumínio composto modificado - ACM) quanto na parte transparente de uma edificação (vidro FV em substituição ao vidro simples e/ou duplo).

O ACM foi o revestimento escolhido para representar os materiais usuais de revestimento opaco em função dos seguintes critérios:

(a) seu caráter de inovação;

(b) sua grande demanda de aplicação em espaços comerciais; e

(c) custo elevado.

Esse material de fechamento é utilizado em fachadas como vedação vertical externa, sem função estrutural e constituído por elementos modulados, tal como o SFV.

\section{Tabela 7 - Composição das paredes externas}

\begin{tabular}{|c|c|c|c|c|}
\hline \multirow{13}{*}{$\infty$} & Material & $\begin{array}{l}\text { Espessura } \\
\text { (e): } m\end{array}$ & 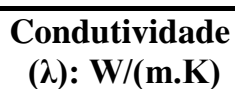 & \multirow{6}{*}{$\begin{array}{l}\text { Com geração de energia } \\
\text { Todas as paredes externas } \\
\mathrm{U}=2,55 \mathrm{~W} /\left(\mathrm{m}^{2} . \mathrm{K}\right) \\
\\
\text { Exceto a voltada para o norte } \\
\mathrm{U}=1,73 \mathrm{~W} /\left(\mathrm{m}^{2} . \mathrm{K}\right)\end{array}$} \\
\hline & $\begin{array}{l}\text { Módulo FV } \\
\text { (vidro) }\end{array}$ & 0,004 & 1,13 & \\
\hline & $\begin{array}{l}\text { Módulo FV } \\
\text { (EVA - sup) }\end{array}$ & 0,001 & 0,15 & \\
\hline & $\begin{array}{l}\text { Módulo FV } \\
\text { (silício) }\end{array}$ & 0,00037 & 148 & \\
\hline & $\begin{array}{l}\text { Módulo FV } \\
\text { (EVA - inf) }\end{array}$ & 0,001 & 0,15 & \\
\hline & $\begin{array}{l}\text { Módulo FV } \\
\text { (Tedlar) }\end{array}$ & 0,0002 & 0,24 & \\
\hline & $\begin{array}{l}\text { Módulo FV } \\
\text { (alumínio) }\end{array}$ & 0,03 & 237 & \multirow{7}{*}{$\begin{array}{l}\text { Planta baixa } \\
\text { esquemática }\end{array}$} \\
\hline & $\begin{array}{l}\text { Câmara de ar } \\
\text { de } 10 \mathrm{~cm}\end{array}$ & \multicolumn{2}{|c|}{$\begin{array}{l}\text { Resistência térmica } \\
\text { de } 0,17 \mathrm{~m}^{2} . \mathrm{K} / \mathrm{W}\end{array}$} & \\
\hline & Reboco & 0,025 & 1,15 & \\
\hline & $\begin{array}{l}\text { Alvenaria } \\
\text { cerâmica }\end{array}$ & 0,015 & 0,70 & \\
\hline & Câmara de ar & \multicolumn{2}{|c|}{$\begin{array}{l}\text { Resistência térmica } \\
\text { de } 0,16 \mathrm{~m}^{2} . \mathrm{K} / \mathrm{W}\end{array}$} & \\
\hline & $\begin{array}{l}\text { Alvenaria } \\
\text { cerâmica }\end{array}$ & 0,015 & 0,70 & \\
\hline & Argamassa & 0,020 & 1,15 & \\
\hline
\end{tabular}


Figure 6 - Modelos simulados

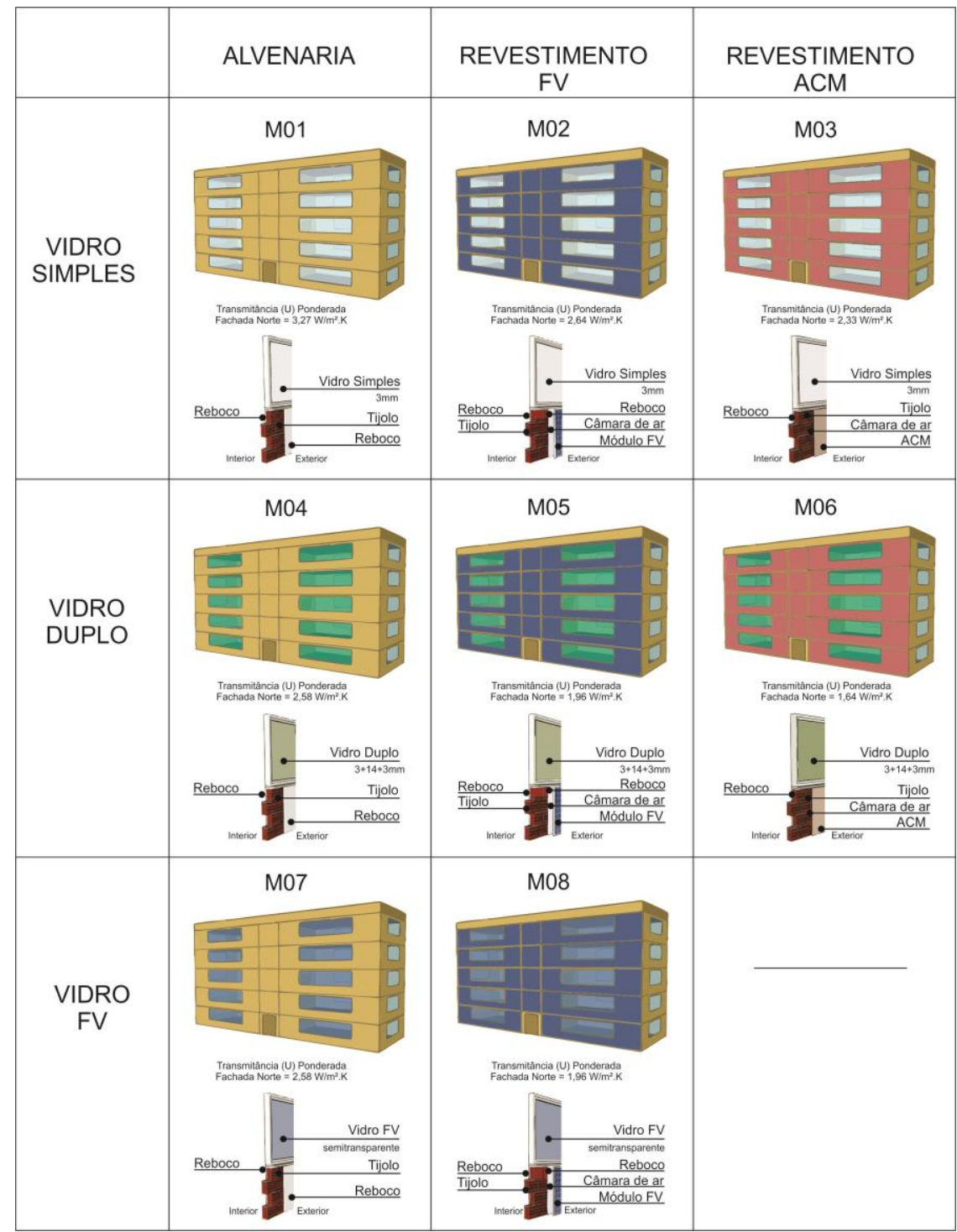

Assim, o M01 foi o modelo base de alvenaria e vidro simples. No M02, foi inserido o revestimento FV apenas nas partes opacas do modelo base, mantendo o vidro simples. O M03 foi o modelo base revestido de ACM, mantendo o vidro simples. Logo, nos modelos M04, M05 e M06, foi feita a substituição do vidro simples pelo vidro duplo dos modelos M01, M02 e M03, respectivamente. Já no M07, teve-se a substituição apenas da parte transparente do modelo base por VFV. E, no modelo M08, foi feita a substituição tanto da parte opaca quanto da parte transparente por tecnologias FV, com o objetivo de comparar toda a composição da fachada tradicional em substituição por uma FSFV.

Em relação à parte opaca, o revestimento FV foi configurado de acordo com a tecnologia disponível na região de Pelotas, RS, buscando verificar seu potencial de geração FV, conforme Tabela 8. Trata-se do módulo CS6P - 260P da CanadianSolar, com tecnologia de poli-cristalino, dimensões (CxLxH) de 1.638 mm x $982 \mathrm{~mm}$ x $40 \mathrm{~mm}$. A Tabela 9 especifica as propriedades térmicas dos componentes de módulos FV opacos.

Para a parte transparente do modelo, foram estudados VFV em substituição de vidros simples e duplos, também considerados usuais na construção civil. Para isso foram utilizados os VFV com grau de transparência de 30\%, da Solarterra, conforme as especificações da Tabela 10. 
Tabela 8 - Especificações do módulo opaco

\begin{tabular}{c|c|c|c}
\hline Módulos & Tecnologia & Eficiência & Substrato \\
\hline $\begin{array}{c}\text { CanadianSolar } \\
\text { CS6P }-260 \mathrm{P}\end{array}$ & $\mathrm{p}-\mathrm{Si}$ & $16,16 \%$ & Rígido, com moldura \\
\hline
\end{tabular}

Tabela 9 - Propriedades térmicas do módulo opaco

\begin{tabular}{l|c|c|c|c}
\hline $\begin{array}{c}\text { Componentes/ } \\
\text { Camadas }\end{array}$ & $\begin{array}{c}\text { Espessura } \\
\text { equivalente }(\mathbf{m m})\end{array}$ & $\begin{array}{c}\text { Condutividade } \\
(\mathbf{W} / \mathbf{m . k})\end{array}$ & $\begin{array}{c}\text { Densidade } \\
\left(\mathbf{k g} / \mathbf{m}^{\mathbf{3}}\right)\end{array}$ & $\begin{array}{c}\text { Calor específico } \\
(\mathbf{J} / \mathbf{( k g . k}))\end{array}$ \\
\hline Vidro & 4,00 & 1,13 & 2300 & 600 \\
EVA superior & 1,00 & 0,15 & 1800 & 600 \\
Silício & 0,37 & 148 & 2300 & 712 \\
EVA inferior & 0,50 & 0,15 & 1800 & 600 \\
Tedlar & 0,20 & 0,24 & 2100 & 600 \\
Alumínio & 30,00 & 237 & 2700 & 903 \\
\hline
\end{tabular}

Tabela 10 - Especificações do módulo transparente

\begin{tabular}{c|c|c|c}
\hline Módulos & Tecnologia & Eficiência & Substrato \\
\hline $\begin{array}{c}\text { BIPV Solarterra } \\
270 \mathrm{Wp}\end{array}$ & $\mathrm{m}-\mathrm{Si}$ & $18,5 \%$ & Rígido, sem moldura \\
\hline
\end{tabular}

\section{Simulação computacional e análise energética}

Foram simulados todos os casos propostos (Figura 6), observando o consumo energético (kWh/ano) em cada situação. Este foi analisado através da climatização artificial do edifício, levando em conta que os prédios comerciais tendem a possuir aumento de temperatura durante o horário de expediente, em função das atividades e dos equipamentos, necessitando, assim, resfriar após esse período.

\section{Análise de geração de energia}

A análise FV foi verificada através de dois métodos para uma validação, pois segundo Youssef et al. (2016) o EnergyPlus é confirmado como um excelente programa de análise de consumo de energia, porém não é o mais confiável entre as ferramentas de desempenho do SFV. Embora o estudo da Cepel (CENTRO..., 2014) afirme que o EnergyPlus tem "precisão suficiente para as análises iniciais e para a opção de tecnologias".

Assim, um dos métodos foi a simulação no EnergyPlus, em que o SFV foi configurado no modo simples, tendo sido indicada a eficiência com que as superfícies determinadas converteriam a radiação solar incidente em eletricidade, sem a necessidade de especificar o arranjo dos módulos. No outro método, a geração FV foi dada através de cálculo, utilizando os dados de radiação solar incidente do programa Radiasol e o banco de dados do Atlas Brasileiro de Energia Solar (PEREIRA et al., 2017). Esse cálculo envolve dados de disponibilidade de irradiação solar local, e leva em consideração o SFV adotado, baseando-se no rendimento e na potência instalada. Sendo assim, foi possível calcular a quantidade de energia produzida por cada modelo no período desejado. O cálculo realizado deu-se por meio da Equação 1:

$\mathrm{E}=\mathrm{G} \times \mathrm{r} \times \mathrm{Pcc}$

Eq. 1

Onde:

E é a geração FV (kWh/dia);

$\mathrm{G}$ é a irradiação diária recebida no plano do painel $\mathrm{FV}\left(\mathrm{kWh} / \mathrm{m}^{2} /\right.$ dia $)$, dividida pela irradiância de referência de $1 \mathrm{~kW} / \mathrm{m}^{2}$, expressa em número de horas (h) por dia;

r é o rendimento do sistema (inversor e conexões); e

Pcc é a potência do sistema em corrente contínua $(\mathrm{kW})$.

A irradiação diária $\left(\mathrm{kWh} / \mathrm{m}^{2} / \mathrm{dia}\right)$ obteve-se a partir de dados do programa Radiasol, no qual é possível também obter os dados anuais $\left(\mathrm{kWh} / \mathrm{m}^{2} / \mathrm{ano}\right)$, mais usuais no setor. $\mathrm{O}$ rendimento adotado foi de 0,80 , por ser um valor comumente recomendado na literatura (MIZGIER et al., 2006; ZOMER, 2010). Através da 
Equação 1, o valor estimado de geração energética diária foi calculado. Pode-se obter o valor mensal ou anual multiplicando-se esse resultado pelo número de dias que se deseja.

A Pcc foi obtida a partir do número de módulos, multiplicando esse valor por sua potência nominal, conforme a Equação 2:

$\mathrm{Pcc}=\mathrm{n}^{\mathrm{o}} \mathrm{x}$ Pot. Nom.

Eq. 2

Onde:

Pcc é a potência instalada $(\mathrm{kWp})$;

$\mathrm{n}^{\mathrm{o}}$ é a quantidade de módulos FV que cabem em determinada área; e

Pot. Nom. é a potência nominal do módulo FV em kW.

Para se chegar à quantidade de módulos, dividiu-se a área total disponível pela área individual de um módulo.

\section{Análise de viabilidade econômica}

Com base nos dados de saída do programa EnergyPlus, considerando o consumo da edificação, como também dados dos cálculos da energia gerada pelos módulos FV e os orçamentos solicitados a empresas de Pelotas, RS, e região, foi desenvolvida uma análise de viabilidade financeira. É importante ressaltar que por desconhecimento, o custo dessa tecnologia acaba por se limitar ao equipamento e à implantação do sistema, deixando de lado a quantificação de economia de material de revestimento e/ou fechamento vertical e de energia gerada. Para essa viabilidade financeira foram utilizados dois indicadores:

(a) payback simples (PB); e

(b) payback descontado (PBD).

Como variáveis principais dos cenários financeiros foram adotadas uma taxa mínima de atratividade (TMA) equivalente à Selic (Sistema Especial de Liquidação e Custódia - taxa básica de juros) em agosto de 2018, de $6,5 \%$ ao ano, e um período de retorno de investimento de 25 anos - equivalente ao período ao qual o fabricante oferece garantia aos módulos FV. O método do payback, ou prazo de retorno, fornece um número de períodos do fluxo de caixa em questão nos quais o somatório dos benefícios se iguala ao somatório dos custos (HIRSCHFELD, 2007). O payback simples foi obtido a partir da fração do investimento realizado sobre o custo anual de energia economizada, conforme a Equação 3. Esse método permite analisar a recuperação do investimento ao longo do tempo, sem considerar a variação monetária.

PBsimples $=\frac{I}{C}$

Eq. 3

Onde:

PBsimples: payback simples (anos);

I: Investimento adicional $(\mathrm{R} \$)$; e

C: Custo da energia economizada (R\$ano).

A variação do dinheiro através do tempo sofre sempre uma compensação chamada juros. O payback descontado analisa o prazo de retorno do capital investido, considerando juros. O dinheiro recuperado, através da economia de energia, também sofre variação ao longo do tempo. Para essa análise financeira proposta utilizou-se para o payback simples e o payback descontado com três diferentes taxas de referência neste cálculo, considerando-se um conjunto de doze meses entre setembro de 2017 e agosto de 2018, saber: caderneta de poupança, com acúmulo de 4,55\%; Índice Nacional de Custos da Construção no Mercado (INCC), com acúmulo de 3,75\%; e o Custo Unitário Básico para prédios comerciais, salas e lojas até oito pavimentos, com padrão normal, no estado do Rio Grande do Sul - CUB/RS CSL-8N, com acúmulo de $5,66 \%$.

Como parte dessa análise foram solicitados 3 orçamentos de módulos FV opacos e semitransparentes, assim como dos diferentes vidros utilizados nos modelos. Tanto para a simulação quanto para os orçamentos solicitados não foram levadas em conta particularidades relativas à distribuição estética e instalação. 


\section{Comparação dos resultados}

Nesta etapa, foram apresentadas as simulações dos diferentes modelos comparando-os entre si, buscando verificar as potencialidades de cada um e as variações entre os resultados, tais como: consumo total, desempenho energético através do consumo pela climatização, geração FV e tempo de retorno do investimento.

\section{Resultados e discussões}

\section{Módulos FV na fachada}

Conforme já exposto, a disposição dos módulos FV na fachada não parte da situação ideal, que seria esses posicionados na mesma inclinação da latitude local $\left(30^{\circ}\right)$. Na Figura 7 são apresentados os dados obtidos pelo programa Radiasol, no qual se tem a diferença do nível de irradiação solar entre a posição ideal $\left(30^{\circ}\right)$ e a proposta $\left(90^{\circ}\right)$. A Figura 7 possibilita confirmar que a fachada, mesmo na orientação ideal (norte), porém estando a $90^{\circ}$, apresenta redução no potencial de geração anual do sistema em aproximadamente $50 \%$, em função da menor quantidade de irradiação solar que atinge essa superfície.

Pode-se observar que na situação real proposta a irradiância média é mais uniforme, embora mais baixa. Já na situação ideal têm-se os picos nos meses referentes ao verão, enquanto nos meses de maio a julho, ou seja, no início do inverno, em que a altura solar é menor, as duas curvas ficam muito próximas. Nesse período, a fachada é mais exposta à radiação solar, porém a quantidade de radiação é significantemente menor quando comparada ao verão, como, por exemplo, no mês de janeiro, que se tem irradiância de 6

\section{Consumo e desempenho energético dos 8 casos}

A partir dos resultados das simulações dos 8 modelos, com e sem módulos FV na fachada norte, é possível analisar o desempenho energético da edificação através da climatização artificial e do consumo total. A Figura 8 apresenta o consumo total, assim como a especificação do consumo de aquecimento e de resfriamento de cada modelo, mostrando o resultado para as diferentes possibilidades de substituição dos materiais usuais pela utilização da tecnologia FV, tanto na parte opaca quanto na transparente.

É possível verificar inicialmente, na Figura 8, que o modelo com o menor consumo total foi o M06 $(\mathrm{ALV}+\mathrm{ACM}+\mathrm{VD})$. O que consumiu menos com aquecimento foi o M05 (ALV+FV+VD) e o que menos necessitou de refrigeração foi o M03 (ALV+ACM+VS). Essa análise parte do entendimento do comportamento térmico de um edifício de escritórios. A questão de isolamento térmico em prédios comerciais nem sempre é interessante, pelo fato da necessidade do resfriamento natural deste à noite, para que no dia seguinte o calor do dia anterior não tenha ficado retido na massa térmica da edificação. Assim, analisando o M02, o maior consumo pode ter ocorrido, possivelmente, em função do isolamento proporcionado à fachada norte $\left(\mathrm{U}_{\text {ponderada }}=2,80 \mathrm{~W} / \mathrm{m}^{2} . \mathrm{K}\right)$ através do $\mathrm{SFV}$. O maior isolamento térmico dificultou as perdas de calor da edificação à noite. Isso pode também explicar a necessidade de menos aquecimento durante o dia, porém houve grande consumo com refrigeração.

Figura 7 - Irradiância média real e ideal

\section{IRRADIÂNCIAMÉDIA (kWh/m²/dia)}

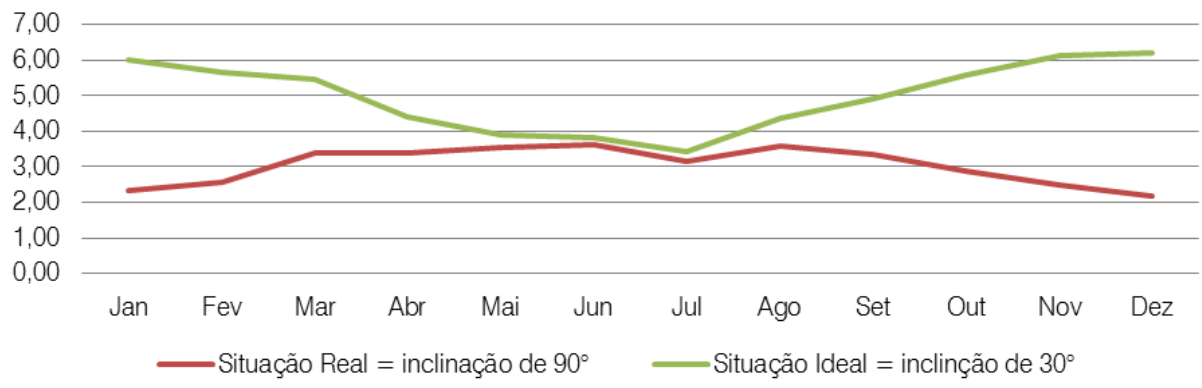


Figure 8 - Consumo e desempenho energético com dados do EnergyPlus CONSUMO E DESEMPENHO ENERGÉTICO

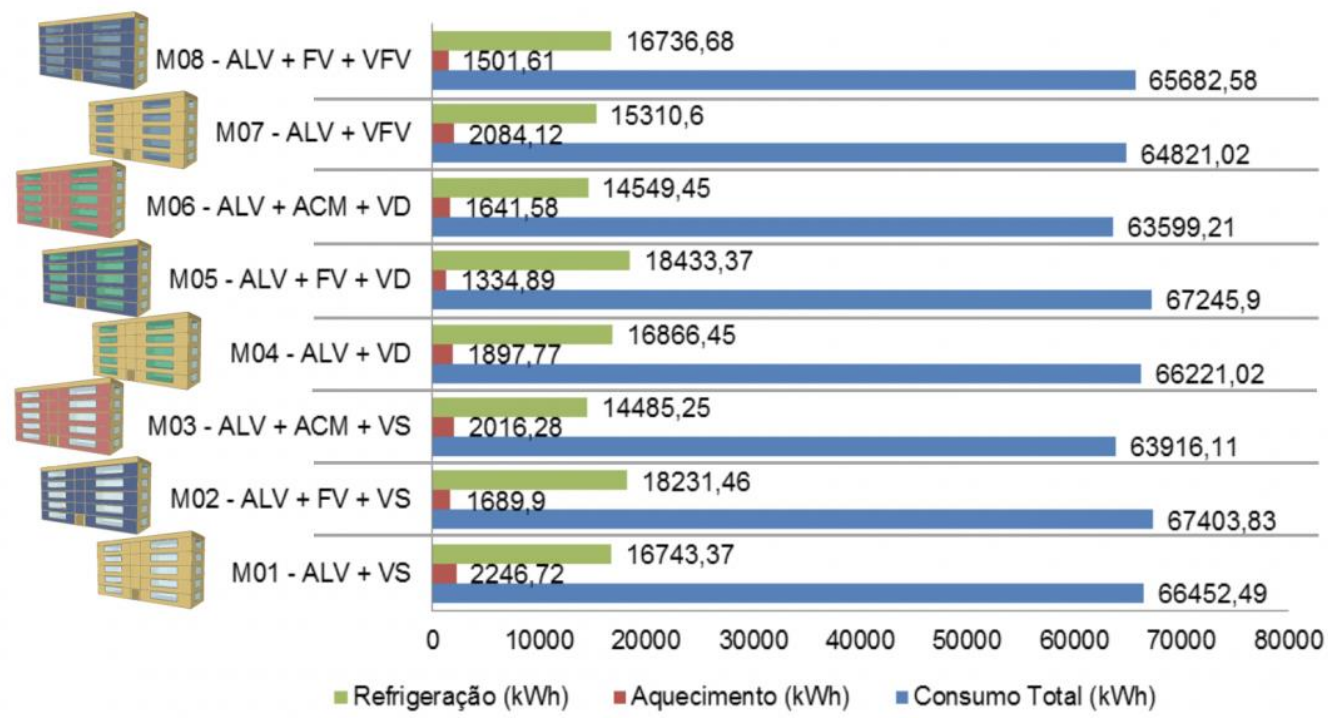

O M01 apresentou maior consumo em aquecimento entre os modelos. Isso provavelmente ocorreu pela alta transmitância térmica da fachada $\left(\mathrm{U}_{\text {ponderada }}=3,40 \mathrm{~W} / \mathrm{m}^{2} . \mathrm{K}\right)$, podendo haver grandes trocas com o ambiente externo, colaborando para maior perda de calor pela edificação. Já o M05 foi o que mais necessitou de refrigeração, justificável em função do isolamento $\left(\mathrm{U}_{\text {ponderada }}=2,00 \mathrm{~W} / \mathrm{m}^{2} \cdot \mathrm{K}\right)$ proporcionado ao envelope através do SFV somado aos VDs, o que pode ter levado à dificuldade de trocas de calor pelos fechamentos da edificação.

A Figura 9 apresenta a comparação do consumo e desempenho energético entre os modelos, buscando comparar os sistemas usuais de construção civil com os SFV, sejam eles nas partes opacas, transparentes ou em ambas.

Analisando a Figura 9, ao comparar a substituição apenas das partes transparentes, a partir dos vidros simples do modelo base M01 (ALV+VS) por vidros FV no M07 (ALV+VFV), tem-se a redução nas três variáveis analisadas: consumo total, refrigeração e aquecimento. A queda na refrigeração pode ter ocorrido em função de o VFV ser semitransparente, o que diminui a incidência solar. Já a redução com aquecimento pode ser devido ao isolamento proporcionado pelo VFV. Já quando a substituição trata dos vidros duplos do M04 (ALV+VD), há aumento no consumo de aquecimento, mas redução nas outras duas variáveis do M07 $(\mathrm{ALV}+\mathrm{VFV})$. Esse aumento no aquecimento pode estar ligado à semitransparência do VFV.

$\mathrm{Na}$ substituição das partes opacas, tanto quando comparados os modelos M02 (ALV+FV+VS) e M03 $(\mathrm{ALV}+\mathrm{ACM}+\mathrm{VS})$ quanto M05 (ALV+FV+VD) com M06 (ALV+ACM+VD), o comportamento dos modelos foi o mesmo, tendo aumento no consumo total e refrigeração, e redução no aquecimento. A causa provável pode ter sido o isolamento proporcionado ao envelope através do SFV, e/ou a diminuição da absortância da fachada, o que pode ter aumentado a necessidade de refrigeração. Em contrapartida, também pode ter proporcionado a queda com consumo para aquecimento.

Também, na substituição de sistemas completos (partes opacas e transparentes), o comportamento dos modelos foi semelhante. Quando comparados, tanto o M03 (ALV+ACM+VS) quanto o M06 $(\mathrm{ALV}+\mathrm{ACM}+\mathrm{VD})$ com o M08 (ALV+FV+VFV), houve aumento do consumo total e refrigeração, assim como redução com aquecimento.

Assim, esses resultados demonstram uma tendência quanto aos SFV para esses modelos com as configurações estabelecidas para este estudo, onde aumentam o consumo total e a refrigeração, e reduzem o aquecimento, exceto nos casos nos quais se trata apenas dos VFV, situações que apresentaram o comportamento oposto, reduzindo consumo total e refrigeração.

Esses resultados apontam que as alternativas ligadas aos VFV são interessantes para substituir os materiais usuais da construção civil na parte transparente da edificação, tratando-se da ZBB2, onde Pelotas está inserida. 
Figure 9 - Consumo e desempenho energético com dados da simulação computacional

\section{PROPOSTAS}

\begin{tabular}{|c|c|c|c|c|}
\hline \multicolumn{5}{|c|}{ Comparação do consumo e desempenho energético entre os sistemas } \\
\hline 1 & $\begin{array}{c}\mathrm{M} 01 \\
(\mathrm{ALV}+\mathrm{VS})\end{array}$ & $\begin{array}{l}\text { consumo: } 66.452,49 \mathrm{kWh} \\
\text { refrigeração: } 16.743,37 \mathrm{kWh} \\
\text { aquecimento: } 2.246,72 \mathrm{kWh}\end{array}$ & $\begin{array}{c}\equiv \\
\text { M07 } \\
(\mathrm{ALV}+\mathrm{VFV})\end{array}$ & $\begin{array}{l}\downarrow \text { consumo: } 64.821,02 \mathrm{kWh} \\
\downarrow \text { refrigeração: } 15.310,60 \mathrm{kWh} \\
\downarrow \text { aquecimento: } 2.084,12 \mathrm{kWh}\end{array}$ \\
\hline 2 & $\begin{array}{c}\equiv \\
\text { M04 } \\
(\mathrm{ALV}+\mathrm{VD})\end{array}$ & $\begin{array}{l}\text { consumo: } 66.221,02 \mathrm{kWh} \\
\text { refrigeração: } 16.866,45 \mathrm{kWh} \\
\text { aquecimento: } 1.897,77 \mathrm{kWh}\end{array}$ & $\begin{array}{c}=2 \mathrm{E} \\
\mathrm{M} 07 \\
(\mathrm{ALV}+\mathrm{VFV})\end{array}$ & $\begin{array}{l}\downarrow \text { consumo: } 64.821,02 \mathrm{kWh} \\
\downarrow \text { refrigeração: } 15.310,60 \mathrm{kWh} \\
\uparrow \text { aquecimento: } 2.084,12 \mathrm{kWh}\end{array}$ \\
\hline 3 & $\underset{\substack{M 02 \\
(A L V+F V+V S)}}{E}$ & $\begin{array}{l}\uparrow \text { consumo: } 67.403,83 \mathrm{kWh} \\
\uparrow \text { refrigeração: } 18.231,46 \mathrm{kWh} \\
\downarrow \text { aquecimento: } 1.689,90 \mathrm{kWh}\end{array}$ & $\mathbf{X} \underset{\mathrm{M} 03}{\mathrm{E}}$ & $\begin{array}{l}\text { consumo: } 63.916,11 \mathrm{kWh} \\
\text { refrigeração: } 14.485,25 \mathrm{kWh} \\
\text { aquecimento: } 2.016,28 \mathrm{kWh}\end{array}$ \\
\hline 4 & 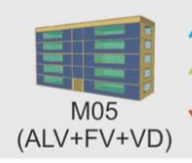 & $\begin{array}{l}\uparrow \text { consumo: } 67.245,90 \mathrm{kWh} \\
\uparrow \text { refrigeração: } 18.433,37 \mathrm{kWh} \\
\downarrow \text { aquecimento: } 1.334,89 \mathrm{kWh}\end{array}$ & $\mathbf{X}$ & $\begin{array}{l}\text { consumo: } 63.599,21 \mathrm{kWh} \\
\text { refrigeração: } 14.549,45 \mathrm{kWh} \\
\text { aquecimento: } 1.641,58 \mathrm{kWh}\end{array}$ \\
\hline 5 & $\begin{array}{c}\bar{E} \equiv \\
\text { M03 } \\
(A L V+A C M+V S)\end{array}$ & $\begin{array}{l}\text { consumo: } 63.916,11 \mathrm{kWh} \\
\text { refrigeração: } 14.485,25 \mathrm{kWh} \\
\text { aquecimento: } 2.016,28 \mathrm{kWh}\end{array}$ & $\begin{array}{c}\text { M08 } \\
(\mathrm{ALV}+\mathrm{FV}+\mathrm{VFV}) \\
\end{array}$ & $\begin{array}{l}\uparrow \text { consumo: } 65.682,58 \mathrm{kWh} \\
\uparrow \text { refrigeração: } 16.736,68 \mathrm{kWh} \\
\downarrow \text { aquecimento: } 1.501,61 \mathrm{kWh}\end{array}$ \\
\hline 6 & $\begin{array}{c}\text { M06 } \\
(A L V+A C M+V D)\end{array}$ & $\begin{array}{l}\text { consumo: } 63.599,21 \mathrm{kWh} \\
\text { refrigeração: } 14.549,45 \mathrm{kWh} \\
\text { aquecimento: } 1.641,58 \mathrm{kWh}\end{array}$ & $\begin{array}{c}\text { M08 } \\
\text { (ALV+FV+VFV) }\end{array}$ & $\begin{array}{l}\uparrow \text { consumo: } 65.682,58 \mathrm{kWh} \\
\uparrow \text { refrigeração: } 16.736,68 \mathrm{kWh} \\
\downarrow \text { aquecimento: } 1.501,61 \mathrm{kWh}\end{array}$ \\
\hline
\end{tabular}

\section{Nota: Legenda:}

ALV = alvenaria;

VS = vidro simples;

$\mathrm{FV}=$ Revestimento FV;

ACM = Alumínio composto modificado;

VD = vidro duplo; $\mathrm{e}$

VFV = vidro FV.

\section{Análise do consumo e geração FV}

A partir das simulações com os módulos FV no programa EnergyPlus foi possível verificar o consumo total anual de cada modelo. Os dados de geração FV foram obtidos através de cálculos baseados nos dados de irradiação solar provenientes do software Radiasol, pois, conforme a literatura revisada, existem divergências sobre a confiabilidade do software EnergyPlus com relação à questão da precisão de valores da geração FV. Os dados de consumo e geração são apresentados na Figura 10.

No modelo M08 apresenta-se uma fachada FV suprindo 56,66\% do consumo estimado, enquanto nos casos M02 e M05, com a utilização dos módulos opacos, apresenta-se uma geração que pode suprir até 41,11\%, e no M07 apenas com VFV temos uma contribuição de aproximadamente 15\%. Entre os modelos analisados a geração está de acordo com o que foi proposto pelos sistemas, mas o destaque é a fachada FV (M08), que supre mais da metade do consumo da edificação, mesmo os módulos não estando posicionados no melhor ângulo de inclinação.

\section{Análise da viabilidade financeira}

Para simplificar a análise econômica referente aos custos de energia elétrica e o tratamento da injeção de excedentes na rede pública de distribuição, a edificação utilizada nesta pesquisa foi considerada como unidade consumidora integral, ou seja, o prédio corresponde a uma unidade consumidora que compreende todas as salas, áreas de circulação e demais dependências, como é comum em se tratando de sedes de grandes empresas. 
Figura 10 - Consumo energético $X$ geração fotovoltaica

\section{CONSUMO (ENERGYPLUS) E GERAÇÃO FV (RADIASOL)}
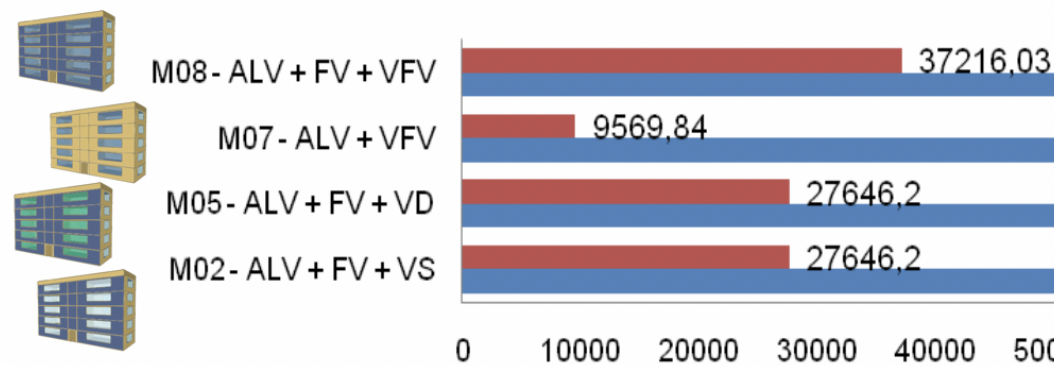

Nota: Legenda:

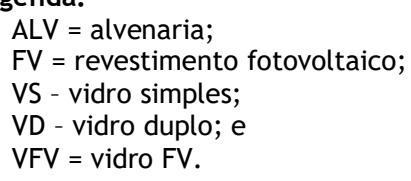

É provável que, discriminadas as cargas de tal unidade consumidora, o total superasse o limite para atendimento em baixa tensão, que é de $75 \mathrm{~kW}$, de acordo com a Resolução Normativa n. 414, da Aneel, de 2010. Dessa forma, a conexão à rede de distribuição demandaria a instalação de transformador próprio no local. Porém, ainda considerando a mesma norma, as unidades consumidoras atendidas em média tensão com potência de transformação igual ou inferior a 112,5 kVA podem optar por faturamento com tarifas de baixa tensão.

Entretanto, os valores de demanda estimada para os cenários simulados não ultrapassaram $38,5 \mathrm{~kW}$. Por essa razão, o transformador que seria dimensionado para atendimento em qualquer um dos modelos estudados não teria potência superior aos 112,5 kVA supracitados. Considerando isso, a escolha de tarifas para os cálculos econômicos deste trabalho recaiu sobre o grupo de baixa tensão, com um único valor para consumo e sem faturamento de demanda contratada. O acréscimo de 2,5\% no consumo e o desconto do mesmo percentual na injeção - previstos na Resolução Normativa já referida - foram desprezados nos cálculos, por se tratar de variação pouco significativa considerando a natureza probabilística do método aqui utilizado.

Seguindo a análise, para que o custo do SFV não se limite ao seu equipamento e à sua implantação, foram feitos orçamentos destes e de materiais usuais na construção civil, fornecidos por empresas da região de Pelotas, RS, para a fachada norte dos modelos já apresentados. Também foram verificadas as tarifas de energia elétrica da concessionária local vigentes em agosto de 2018. Essas informações servem de base para a análise econômica.

A Tabela 11 apresenta os valores obtidos através de orçamentos para os sistemas que estão sendo analisados. Foram feitos três orçamentos para cada material e selecionado para essa análise o valor mais baixo entre eles. O valor da tarifa utilizado foi de $\mathrm{R} \$ 0,50542$, incluindo impostos.

Assim, busca-se analisar a quantificação de economia de material de revestimento, aliada a de energia gerada, ou seja, evidenciar o custo evitado com a utilização dessa tecnologia.

Para essa viabilidade financeira foram utilizados dois indicadores:

(a) payback simples; e

(b) payback descontado.

A Figura 12 resume todas as propostas analisadas apresentando os valores dos sistemas orçados, a diferença do custo de implementação entre esses sistemas e a diferença anual com energia para cada situação. Sobre o retorno de investimento é apresentado em anos, tanto o payback quanto a payback descontado com a taxa do INCC por apresentar um tempo intermediário entre as taxas utilizadas. 
Tabela 11 - Orçamento dos materiais

\begin{tabular}{l|c}
\hline \multicolumn{1}{c|}{ Materiais } & $\begin{array}{c}\text { Valores } \\
\text { (sistemas instalados na fachada norte) }\end{array}$ \\
\hline Vidro simples (VS) & $\mathrm{R} \$ 55.770,00$ \\
Vidro duplo (VD) & $\mathrm{R} \$ 69.700,00$ \\
Módulos FV semitransparentes (VFV) & $\mathrm{R} \$ 85.000,00$ \\
Módulos FV opacos (FV) & $\mathrm{R} \$ 220.000,00$ \\
ACM & $\mathrm{R} \$ 130.000,00$ \\
\hline
\end{tabular}

Figura 12 - Propostas com o tempo de retorno baseado no INCC

\begin{tabular}{|c|c|c|c|c|c|c|c|c|c|}
\hline \multicolumn{10}{|c|}{ RESUMO DAS PROPOSTAS APRESENTADAS } \\
\hline \multicolumn{6}{|c|}{ Propostas e valores de implementação dos sistemas } & $\begin{array}{l}\text { Diferença do } \\
\text { custo de }\end{array}$ & $\begin{array}{l}\text { Diferença } \\
\text { anual com }\end{array}$ & $\begin{array}{c}\text { Payback } \\
\text { (anos) }\end{array}$ & $\begin{array}{c}\text { Payback D. } \\
\text { (anos) }\end{array}$ \\
\hline 1 & $\begin{array}{c}M 01 \\
(A L V+V S)\end{array}$ & $\mathrm{R} \$ 55.770,00$ & $\mathbf{X}$ & $\begin{array}{c}\mathrm{M} 07 \\
(\mathrm{ALV}+\mathrm{VFV})\end{array}$ & $\mathrm{R} \$ 85.000,00$ & $\mathrm{R} \$ 29.230,00$ & $\mathrm{R} \$ 5.661,37$ & 5 & 6 \\
\hline 2 & 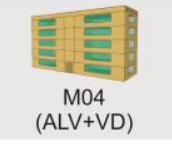 & $\mathrm{R} \$ 69.700,00$ & $\mathbf{X}$ & $\begin{array}{c}= \\
\text { M07 } \\
(\mathrm{ALV}+\mathrm{VFV})\end{array}$ & $\mathrm{R} \$ 85.000,00$ & $\mathrm{R} \$ 15.300,00$ & $\mathrm{R} \$ 5.544,38$ & 2 & 3 \\
\hline 3 & $\underset{\substack{\mathrm{M} 02 \\
\text { (ALV+FV+VS) }}}{\text { 릉 }}$ & $\mathrm{R} \$ 275.770,00$ & $\mathbf{x}$ & $\begin{array}{c}\text { 틀 를 } \\
\text { M03 } \\
(\mathrm{ALV}+\mathrm{ACM}+\mathrm{VS})\end{array}$ & $\mathrm{R} \$ 185.770,00$ & $\mathrm{R} \$ 90.000,00$ & $\mathrm{R} \$ 12.266,25$ & 8 & 10 \\
\hline 4 & $\begin{array}{c}\mathrm{M} 05 \\
(\mathrm{ALV}+\mathrm{FV}+\mathrm{VD})\end{array}$ & $\mathrm{R} \$ 289.700,00$ & $\mathbf{X}$ & $\begin{array}{c}M 06 \\
(A L V+A C M+V D)\end{array}$ & $\mathrm{R} \$ 199.700,00$ & $\mathrm{R} \$ 90.000,00$ & $\mathrm{R} \$ 12.162,90$ & 8 & 10 \\
\hline 5 & 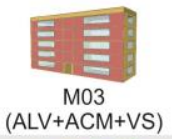 & $\mathrm{R} \$ 185.770,00$ & $\mathbf{X}$ & $\begin{array}{c}\mathrm{M} 08 \\
(\mathrm{ALV}+\mathrm{FV}+\mathrm{VFV})\end{array}$ & $\mathrm{R} \$ 305.000,00$ & $\mathrm{R} \$ 119.230,00$ & $\mathrm{R} \$ 17.972,98$ & 7 & 9 \\
\hline 6 & $\begin{array}{c}M 06 \\
(A L V+A C M+V D)\end{array}$ & $\mathrm{R} \$ 199.700,00$ & $\mathbf{x}$ & $\begin{array}{c}M 08 \\
(A L V+F V+V F V)\end{array}$ & $\mathrm{R} \$ 305.000,00$ & $\mathrm{R} \$ 105.300,00$ & $\mathrm{R} \$ 17.789,82$ & 6 & 7 \\
\hline
\end{tabular}

Assim, partiu-se de substituições simples na fachada norte, apenas das partes transparentes. Tem-se, por exemplo, o vidro duplo sendo substituído, ainda em fase de projeto, por vidro FV e gerando uma economia com a diferença anual com energia de aproximadamente $\mathrm{R} \$ 5.600,00$. Subtraindo esse valor mensalmente do custo da diferença entre os sistemas, o investimento se pagaria de 2 a 3 anos.

Se compararmos a substituição apenas das partes opacas, como se em vez de revestirmos a edificação com ACM utilizarmos o revestimento FV, do mesmo modo que o exemplo anterior, o investimento se pagaria entre 8 e 10 anos. Substituindo tanto a parte opaca quanto a transparente, como na comparação 6, em que a utilização de vidro duplo e revestimento de ACM, usuais em prédios comerciais, seriam substituídas ainda em fase de projeto por módulos FV, o tempo de retorno estaria dentro de um período de 6 a 7 anos, sendo pago com a diferença anual de economia com energia.

Com isso, pode-se entender que existe viabilidade econômica, desde que as variáveis corretas sejam analisadas, e que isso seja feito ainda em fase de projeto.

Sobre a geração FV, esta foi calculada utilizando dados do programa Radiasol. Na fachada apenas com módulos semitransparentes, a contribuição FV em função do consumo estimado foi de aproximadamente $15 \%$. Quando somente com módulos opacos, a contribuição passa a ser de até $41,11 \%$. Porém, quando tratamos de uma FSFV, esta contribui suprindo 56,66\% desse consumo. Com base no trabalho realizado e em consonância com Sorgato el al. (2018) e Didoné et al. (2014), estudos desenvolvidos para o Brasil, foi possível caracterizar a viabilidade da utilização de SFV como também VFV para edifícios de escritórios. 


\section{Conclusão}

Mais que um apelo ambiental, estratégias e soluções de projeto buscam desenvolver construções eficientes, com baixo consumo de energia, em que gerar sua própria energia está entre os objetivos. A tecnologia FV está em pleno desenvolvimento, sendo cada vez mais inserida no ambiente construído, indo além da função de geradora de energia elétrica, também utilizada como elemento de vedação na arquitetura. Esse fato, aliado à contínua redução de custos dos módulos FV e demais equipamentos que compõem o sistema, vem contribuindo para que os módulos passem a ser mais utilizados nos centros urbanos.

A utilização de módulos em fachadas, principalmente em edifícios de escritório, parte da concorrência com outras tecnologias e/ou serviços que normalmente utilizam as coberturas. Entretanto, comparada a outras FRE, esta possibilita a integração com a arquitetura, em função de sua modularidade e apelo estético, que pode ainda atribuir um conceito tecnológico à edificação. Partindo do princípio que os revestimentos são considerados um dos itens percentualmente mais caros de uma obra, utilizar módulos FV, além de evitar o custo com outro material usual de construção, ainda gera energia, agregando assim benefícios econômicos.

Foi possível observar, através de simulações no programa EnergyPlus, que no desempenho energético da edificação a fachada apenas com módulos semitransparentes, utilizados para substituir elementos nas partes transparentes desta, obteve redução uniforme entre as variáveis analisadas (consumo total, aquecimento e refrigeração) quando passou a substituir o vidro simples. Já para as fachadas apenas com módulos opacos substituindo os revestimentos das partes opacas, assim como para as FSFV, quando comparadas com outros modelos, demonstraram uma tendência de aumento do consumo total e da refrigeração, e redução do aquecimento.

Observou-se que o uso de SFV na fachada é interessante para substituir os materiais usuais da construção civil na parte transparente e opaca da edificação, isso se tratando da ZBB2, onde Pelotas está inserida, o que não descarta as outras possibilidades, pois também é necessário considerar a geração FV para uma análise correta das possibilidades dos SFV.

Essas gerações só não são maiores devido à inclinação $\left(90^{\circ}\right)$ dos módulos, que embora não seja o melhor ângulo de captação solar, ainda apresenta uma geração capaz de suprir, como supracitado, com mais da metade do consumo energético do edifício.

Já a análise financeira parte da mesma comparação entre sistemas usuais da construção civil com o SFV, subtraindo do total do seu custo os gastos evitados com o revestimento e/ou fechamento vertical usual que seria utilizado e a energia gerada, ou seja, as variáveis pertinentes.

Assim, foi possível verificar que a tecnologia FV é viável, podendo substituir apenas as partes transparentes (vidros simples) por vidros FV, tendo um retorno pelos métodos payback e payback descontado (INCC) de 5 a 6 anos. Da mesma maneira pode substituir apenas os revestimentos opacos (ACM), nos quais apresenta tempo de retorno entre 8 e 10 anos. Ou substituir um sistema inteiro (ACM e vidros simples), no qual apresenta tempo de retorno entre 5 e 9 anos.

Em todas as comparações apresentadas é importante analisar os sistemas, nos quais os materiais usuais apresentam a desvantagem de servir apenas como revestimento e/ou fechamento vertical, em que o investimento nessa escolha encerra-se na estética que este proporciona, enquanto o SFV, seja ele opaco ou semitransparente, segue gerando energia para a edificação durante toda sua vida útil (no mínimo 20 anos), auxiliando a rede pública, além de ser uma energia produzida de forma limpa. Com isso, pode-se entender que existe viabilidade econômica, desde que as variáveis corretas sejam analisadas, e que isso seja feito ainda em fase de projeto.

\section{Referências}

AGATHOKLEOUS, R. A.; KALOGIROU, S. A. Double skin facades (DSF) and building integrated photovoltaics (BIPV): a review of configurations and heat transfer characteristics. Renewable Energy, v. 89, n. 4, p. 1-14, 2015.

ARA, P. J. S. Desempenho de sistemas de condicionamento de ar com utilização de energia solar em edifícios de escritório. São Paulo, 2010. Dissertação (Mestrado em Engenharia) - Escola Politécnica da Universidade de São Paulo, São Paulo, 2010.

ASSOCIAÇAO BRASILEIRA DE NORMAS TÉCNICAS, ABNT. NBR 16401-1: instalações de arcondicionado: sistemas centrais e unitários: parte 1: projetos das instalações. Rio de Janeiro: 2008. 
CARLO, J. C. Desenvolvimento de metodologia de avaliação da eficiência energética do envoltório de edificações não-residenciais. Florianópolis, 2008. Tese (Doutorado em Engenharia Civil) - Programa de Pós-Graduação em Engenharia Civil, Universidade Federal de Santa Catarina, Florianópolis, 2008.

CATITA, C. et al. Extending solar potential analysis in buildings to vertical facades. Computers \& Geosciences, v. 66, p. 1-12, 2014.

CENTRO DE PESQUISAS DE ENERGIA ELÉTRICA. Guia para eficientização energética nas edificações públicas - Versão 1.0. Coordenador Ministério de Minas e Energia. Rio de Janeiro, 2014.

DÁVI, G. A. Avaliação do comportamento energético de um edifício residencial à energia neto positiva com sistema solar fotovoltaico conectado à rede (SFVCR). Florianópolis, 2013. Dissertação (Mestrado em Engenharia Civil) - Universidade Federal de Santa Catarina, Florianópolis, 2013.

DIAS, L. S. Incorporação de sistemas fotovoltaicos em envoltórias de edificações: tecnologia e arquitetura. São Paulo, 2014. Tese (Doutorado em Arquitetura e Urbanismo) - Universidade de São Paulo, São Paulo, 2014

DIDONÉ, E.L. et al. Estratégias para edifícios de escritório energia zero no Brasil com ênfase em BIPV. Ambiente Construído, Porto Alegre, v. 14, n. 3, p. 27-42, jul./set. 2014.

DOMJAN, S. et al. Fast Modelling of nZEB Metrics of Office Buildings Built with Advanced Glass and BIPV Facade Structures. Energies, v. 12, n. 16, p. 3194, 2019.

ECHEGARAY, F. Understanding stakeholders' views and support for solar energy in Brazil. Journal of Cleaner Production, v. 63, p. 125-133, 2014.

FERREIRA, A. P.; SCOMPARIN, L. E.; CARIGNANI, G. Energia fotovoltaica em edifícios matogrossenses: viabilidade econômica e energética de janelas fotovoltaicas. In: ENCONTRO NACIONAL DE TECNOLOGIA DO AMBIENTE CONSTRUÍDO, 13., Canela, 2010. Anais [...] Canela: ANTAC, 2010.

FRANCO, A. P. Sistemas fotovoltaicos: contextualização e perspectivas para sua massificação no Brasil. Lavras, 2013. Trabalho de conclusão de curso (curso de Pós-Graduação Lato Sensu em Formas Alternativas de Energia) - Pós-Graduação em Formas Alternativas de Energia, Lavras, 2013.

GAVIRIA, L. R. et al. O. Influência da configuração urbana na geração fotovoltaica com sistemas integrados às fachadas. Ambiente Construído, Porto Alegre, v. 13, n. 4, p. 7-23, out./dez. 2013.

GOLDEMBERG, J.; LUCON, O. Energia e meio ambiente no Brasil. Estudos Avançados, v. 21, p. 7-20, 2007.

HEINSTEIN, P. et al. Building integrated photovoltaics (BIPV): review, potentials, barriers and myths. Green, v. 3, n. 2, p. 125-156, 2013.

HIRSCHFELD, H. Engenharia econômica e análise de custos. São Paulo: Atlas, 2007.

LAI, C.; HOKOI, S. Solar façades: a review. Building and Environment, v. 91, p. 152-165, 2015.

MEDEIROS, J. S. The Introduction of a ceramic panel ventilated façade system in Brazil: from the idea to the practice. In: CONGRESO MUNDIAL DE LA CALIDAD DEL AZULEJO Y DEL PAVIMENTO CERÁMICO, 12., Castellón, 2012. Proceedings [...] Castellón: Cámara Oficial de Comercio, Industria y Navegación, 2012.

MEDVED, S. et al. The dynamic thermal response model and energy performance of multi-layer glass and BIPV facade structures. Energy and Buildings, v. 188, p. 239-251, 2019.

MIZGIER, M. O. Potencial da geração fotovoltaica frente ao consumo de energia elétrica em edificações residenciais brasileiras. In: ENCONTRO NACIONAL DE TECNOLOGIA DO AMBIENTE CONSTRUÍDO, Florianópolis, 2006. Anais [...] Florianópolis: ANTAC, 2006.

OLIVER, M.; JACKSON, T. Energy and economic evaluation of building-integrated photovoltaics. Energy, v. 26, p. 431-439, 2001.

ORDENES, M. et al. Metodologia utilizada na elaboração da biblioteca de materiais e componentes construtivos brasileiros para simulações no Visualdoe-3.1. Relatório Interno - Departamento de Engenharia Civil, Universidade Federal de Santa Catarina, Florianópolis, 2003. Disponível em: http://www.labeee.ufsc.br/node/266. Acesso em: 15 jan. 2020. 
PENG, C. et al. Building-integrated photovoltaics (BIPV) in architectural design in China. Energy and Building, v. 43, p. 3592-3598, 2011.

PEREIRA, E. et al. Atlas Brasileiro de Energia Solar. 2. ed. São José dos Campos: INPE, 2017.

RÜTHER, R. Edifícios solares fotovoltaicos: o potencial da geração solar fotovoltaica integrada a edificações urbanas e interligada à rede elétrica pública no Brasil. Florianópolis: LABSOLAR, 2004.

SANTOS, A. H. C. Avaliação técnica e financeira da geração fotovoltaica integrada à fachada de edifícios de escritórios corporativos na cidade de São Paulo. São Paulo, 2015. Tese (Doutorado em Ciências) - Programa de Pós-Graduação em Energia do Instituto de Energia e Ambiente, Universidade de São Paulo, São Paulo, 2015.

SORGATO, M. J. et al. Technical and economic evaluation of thin-film CdTe building-integrated photovoltaics (BIPV) replacing façade and rooftop materials in office buildings in a warm and sunny climate. Renewable Energy, v. 118, p. 84-98, 2018.

STRONG, S. Building integrated photovoltaics (BIPV). Whole building design guide, v. 9, 2010.

UNIVERSIDADE FEDERAL DE PELOTAS. Normais Climatológicas de Pelotas, 1971 a 2000.

Disponível em: https://wp.ufpel.edu.br/agrometeorologia/informacoes/clima-de-pelotas/. Acesso em: 25 set. 2019.

YANG, R. J.; ZOU, P. X. W. Building integrated photovoltaics (BIPV): costs, benefits, risks, barriers and improvement strategy. International Journal of Construction Management, v. 16, p. 39-53, 2015.

YOUSSEF, A. M. A. et al. Comparative analysis of simulation and optimization tools for building integrated photovoltaics (BIPV). Journal of Engineering Sciences, v. 44, p. 363-377, 2016.

ZOMER, C. D. Megawatt solar: geração solar fotovoltaica integrada a uma edificação inserida em um meio urbano e conectada à rede elétrica: estudo de caso: edifício sede da Eletrosul, Florianópolis - Santa Catarina. Florianópolis, 2010. Dissertação (Mestrado em Engenharia Civil) - Programa de Pós-Graduação em Engenharia Civil, Universidade Federal de Santa Catarina, Florianópolis, 2010.

\author{
Lívia Vasques Bender \\ Laboratório de Conforto e Eficiência Energética | Universidade Federal de Pelotas | Rua Benjamim Constant 1359, Centro | Pelotas - RS \\ Brasil | CEP 96020-010 | Tel.: (53) 3284-5500 | E-mail: liviabender@hotmail.com \\ Rodrigo Karini Leitzke \\ Laboratório de Conforto e Eficiência Energética | Universidade Federal de Pelotas | E-mail: rodrigokarinileitzke@gmail.com \\ Julye Ramalho de Freitas \\ Laboratório de Conforto e Eficiência Energética | Universidade Federal de Pelotas | E-mail: juramalhof@hotmail.com \\ Eduardo Grala da Cunha \\ Departamento de Tecnologia da Construção | Universidade Federal de Pelotas | E-mail: eduardogralacunha@yahoo.com.br \\ Isabel Tourinho Salamoni \\ Departamento de Tecnologia da Construção | Universidade Federal de Pelotas | E-mail: isalamoni@gmail.com
}

\author{
Ambiente Construído \\ Revista da Associação Nacional de Tecnologia do Ambiente Construído \\ Av. Osvaldo Aranha, $99-3^{\circ}$ andar, Centro \\ Porto Alegre - RS - Brasil \\ CEP 90035-190 \\ Telefone: +55 (51) 3308-4084 \\ Fax: +55 (51) 3308-4054 \\ www.seer.ufrgs.br/ambienteconstruido \\ E-mail: ambienteconstruido@ufrgs.br
}

